\title{
Temporal variability of subsurface stormflow formation*
}

\author{
P. M. Kienzler and F. Naef \\ Institute of Environmental Engineering, ETH Zurich, Zurich, Switzerland \\ *Invited contribution by P. M. Kienzler, one of the EGU outstanding Young Scientist Award winners 2006.
}

Received: 19 June 2007 - Published in Hydrol. Earth Syst. Sci. Discuss.: 5 July 2007

Revised: 20 December 2007 - Accepted: 13 January 2008 - Published: 18 February 2008

\begin{abstract}
Subsurface stormflow (SSF) can play a key role for the runoff generation at hillslopes. Quantifications of SSF suffer from the limited ability to predict how SSF is formed at a particular hillslope and how it varies in time and space. This study concentrates on the temporal variability of SSF formation. Controlled sprinkling experiments at three experimental slopes were replicated with varying precipitation intensity and varying antecedent precipitation. SSF characteristics were observed with hydrometric measurements and tracer experiments. SSF response was affected in different ways and to varying degree by changes of precipitation intensity and antecedent precipitation. The study showed that the influence of antecedent precipitation on SSF response depends on how SSF is formed at a particular hillslope. As formation of SSF was hardly influenced by the increase of precipitation intensity subsurface flow rates were not increased by higher intensity. However, timing and relevance of subsurface flow response changed substantially at different precipitation intensities, because saturation and flow formation occurred above the soil-bedrock interface, but also within the topsoil depending on precipitation intensity.
\end{abstract}

\section{Introduction}

Subsurface stormflow (SSF) can play a key role for the runoff generation on hillslopes (see reviews by Jones and Connelly, 2002; Weiler et al., 2006). Considerable contributions to stream flow have been observed from SSF in lateral preferential flow paths where water flows with much higher flow velocities than in the surrounding soil matrix (e.g. McDonnell, 1990; Peters et al., 1995). Such flow paths can be formed either by biological activity or by subterranean erosion at

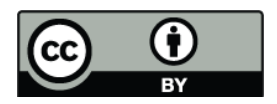

Correspondence to: P. M. Kienzler (kienzler@ifu.baug.ethz.ch) the soil-bedrock interface and show large variation regarding diameter, shape, length and network form. Observations of lateral preferential flow paths range from flow in a thin saturated layer with high permeability (Peters et al., 1995; Scherrer et al., 2007) to runoff along microchannels above the bedrock surface (Noguchi et al., 2001), flow in fractures within the bedrock (Anderson et al., 1997), pipe flow at the soil-bedrock interface (McDonnell, 1990) and flow through a self-organising interconnection of macropores embedded in the soil matrix (Sidle et al., 2000). To avoid confusion by this multiple terminology, in this paper "macropores" are defined as vertical preferential flow paths and "pipes" or "highly permeable layers" as lateral preferential flow paths.

While many studies have documented the large variation of subsurface flow paths, there is a lack of a conceptual framework to predict which intensity of SSF can be expected at a particular hillslope in terms of flow rates and timing of the flow. Quantifications of SSF are further hampered by the high spatial variability of the invisible subsurface flow paths. Hence, considerable research has been directed to the conceptual understanding of SSF formation (e.g. McDonnell, 1990; Sidle et al., 2000; Kienzler and Naef, 2008) as well as to the question where subsurface flow occurs (Jones et al., 1997; Scherrer and Naef, 2003) and how to detect the spatial variability of subsurface flow paths (Woods and Rowe, 1996). However, few studies have concentrated on how the formation of SSF varies in time and is influenced by antecedent precipitation and precipitation intensity in individual rainfall events.

In general, temporal variance of precipitation is important for runoff formation mechanisms related to saturation. Kirkby (1969) described overland flow as a result of saturation excess of the soil and pointed out the significance of antecedent soil moisture for this process. The relation between saturation and SSF formation was conceptualised by McDonnell (1990). He explained the initiation of lateral subsurface flow in soil pipes as a result of perched saturation above

Published by Copernicus Publications on behalf of the European Geosciences Union. 


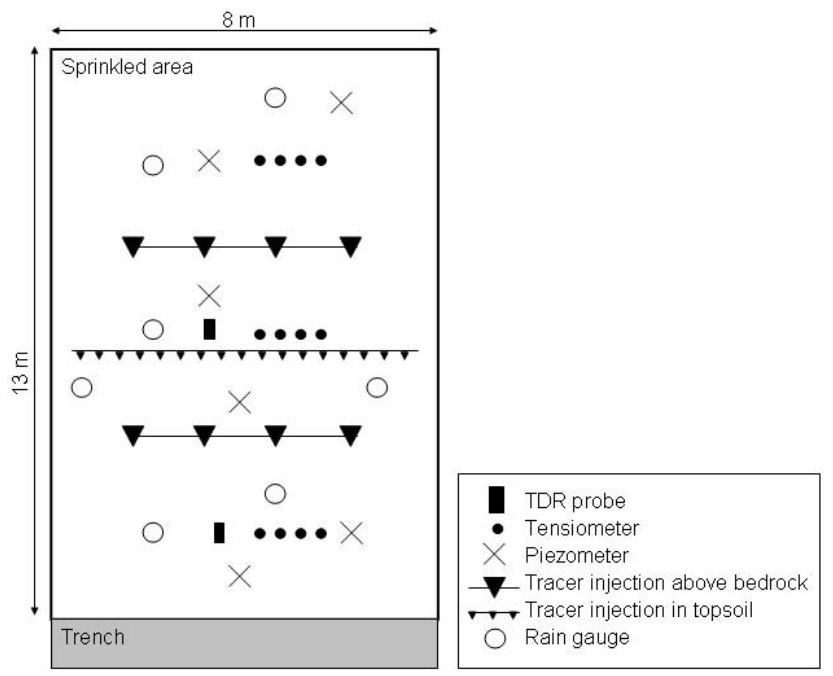

Fig. 1. Experimental set-up during the sprinkling experiments in a view from above. Installation depths of the probes and tracer injection varied at different experimental slopes according to soil depth.

impermeable bedrock. Correlation of SSF formation with antecedent precipitation has been shown by several studies (Whipkey, 1967; Lynch et al., 1979; Uchida et al., 1999). Beven and Germann (1982) pointed to the relation between antecedent soil moisture and preferential infiltration in that "higher initial soil moisture content in the soil may also allow deeper penetration along the macropores by reducing the lateral losses". Similarly, Bouma et al. (1982) named soil water content as a crucial parameter for the "magnitude of bypass flow". Experimental evidence for this hypothesis comes from Weiler (2001), who observed reduced flow from macropores into the soil matrix, when the soil was wetted before the experiment. Thus, a more intense and faster start of SSF can be expected under wet preconditions, as infiltrating water reaches lateral flow paths quicker and less water is required to trigger subsurface flow.

In a similar way, increased precipitation intensity could lead to a subsequent faster onset of SSF because of a switch from matrix infiltration to macropore infiltration. Beven and Germann (1982) hypothesized that the initiation of macropore flow is related to precipitation intensity. They proposed that macropore flow is initiated from water ponding at the soil surface as soon as the infiltration capability of the soil matrix is surpassed. This conceptual model of macropore flow initiation has since been applied in many detailed numerical models of infiltration and runoff formation (e.g. Zuidema, 1985; Bronstert and Plate, 1997). In fact, experimental studies have provided evidence for the correlation between precipitation intensity and macropore flow (Trojan and Linden, 1992). However, initiation of macropore flow has been observed even during low precipitation intensity as a result of subsurface saturation (Weiler and Naef, 2003).
This study aims to illuminate the relevance of antecedent precipitation and precipitation intensity for subsurface stormflow (SSF) formation. For this purpose, controlled sprinkling experiments on three different experimental slopes were replicated with varying precipitation intensity and antecedent soil moisture. SSF characteristics were observed with hydrometric measurements and tracer experiments. SSF response was affected in different ways and to varying degree by changes of precipitation intensity and antecedent soil moisture. The paper discusses, which site-specific properties were responsible for the different responses and some general conclusions are drawn that may help to assess the temporal variability of SSF during individual rainfall events.

\section{Experimental setup}

Infiltration and runoff formation were monitored on three experimental slopes during sprinkling experiments on areas of $100 \mathrm{~m}^{2}$. Follow-up experiments with similar precipitation intensity were conducted on adjacent days to study the influence of antecedent precipitation on SSF. In each case, the first experiment was conducted under dry weather conditions and the second experiment on the following day with the antecedent precipitation of the first experiment. Table 1 lists details on the antecedent moisture calculated from TDR-measurements and precipitation intensity of the different experiments. Follow-up experiments with high (40$\left.50 \mathrm{~mm} \mathrm{~h}^{-1}\right)$ and low $\left(10 \mathrm{~mm} \mathrm{~h}^{-1}\right)$ precipitation intensities were conducted. Table 2 lists precipitation intensity and antecedent moisture during the different experiments. Subsurface flow was collected above the bedrock in a trench at the lower end of the sprinkled area. Total subsurface flow, outflow from larger pipes and overland flow were measured either with $100 \mathrm{ml}$ tipping bucket gauges or with $45^{\circ}$ Thompson weirs. Twelve tensiometers recorded the matric potential every five minutes at four different depths. They were arranged in three nests $2 \mathrm{~m}, 4 \mathrm{~m}$ and $6 \mathrm{~m}$ upslope the trench face (Fig. 1). Soil moisture content changes were monitored $2 \mathrm{~m}$ and $6 \mathrm{~m}$ upslope the trench face with five-segment TDR probes, which recorded the average moisture content in fiveminute intervals at $0-15 \mathrm{~cm}, 15-30 \mathrm{~cm}, 30-45 \mathrm{~cm}, 45-60 \mathrm{~cm}$ and 60-90 cm depth. Six piezometers recorded water levels within the soil. To determine event and pre-event water fractions in the different runoff components the sprinkling water was traced with the fluorescent dye naphtionate. The natural tracer Radon-222 allowed assessing pre-event water percentages in SSF during natural rainfall events (Kienzler and Naef, 2008). Figure 1 depicts the experimental setup. Locations of the devices varied slightly on the different experimental slopes. At Lutertal, soil moisture content was monitored more closely with 30 additional TDR probes (Retter et al., 2006). Details on the experimental setup and uncertainties of the methods can be found in Kienzler and Naef (2008). 
Table 1. Comparison of experiments with different antecedent precipitation. Details are given of antecedent soil moisture and precipitation intensity as well as water balance estimates for each experimental slope. Soil water storage after drainage relates to soil moisture content $12 \mathrm{~h}$ after sprinkling.

\begin{tabular}{|c|c|c|c|c|c|c|}
\hline \multirow{2}{*}{$\begin{array}{l}\text { Site } \\
\text { Identification in text }\end{array}$} & \multicolumn{2}{|c|}{ Schluessberg } & \multicolumn{2}{|c|}{ Lutertal } & \multicolumn{2}{|c|}{ Im Sertel } \\
\hline & first experime & second experiment & first experiment & second experiment & first experiment & second experiment \\
\hline Precipitation intensity $\left[\mathrm{mm} \mathrm{h}^{-1}\right]$ & 8 & $10 /$ increase to 20 & 11.6 & 14.4 & 8.4 & 8.4 \\
\hline Precipitation sum $[\mathrm{mm}]$ & 89 & 126 & 152 & 98 & 85 & 80 \\
\hline Antecedent soil moisture [mm] & 220 & 240 & 125 & 140 & 540 & 584 \\
\hline Soil water storage after drainage $[\mathrm{mm}]$ & 20 & 33 & 15 & 44 & 44 & 39 \\
\hline Runoff (SSF + OF) [mm] & $23+0$ & $42+1$ & $53+5$ & $28+4$ & $0+0$ & $15+0$ \\
\hline Percolation into bedrock [mm] & 46 & 50 & 80 & 22 & 41 & 26 \\
\hline
\end{tabular}

Table 2. Comparison of experiments with different precipitation intensities. Details are given of antecedent soil moisture and precipitation intensity for each test slope. Soil water storage after drainage relates to the soil moisture content $12 \mathrm{~h}$ after sprinkling.

\begin{tabular}{lcccccc}
\hline Site & \multicolumn{2}{c}{ Schluessberg } & \multicolumn{2}{c}{ Lutertal } & \multicolumn{2}{c}{ Im Sertel } \\
\hline Identification in text & low intensity & high intensity & low intensity & high intensity & low intensity & high intensity \\
\hline Precipitation intensity $\left[\mathrm{mm} \mathrm{h}^{-1}\right.$ ] & 10/increase to 20 & 37 & 11.6 & 50.4 & 8.4 & 50.4 \\
Precipitation sum [mm] & 126 & 164 & 152 & 194 & 80 & 118 \\
Antecedent soil moisture [mm] & 240 & 237 & 125 & 138 & 584 & 613 \\
Soil water storage after drainage [mm] & 33 & 27 & 15 & 66 & 39 & 39 \\
Runoff (SSF + OF) [mm] & $42+1$ & $0+84$ & $53+5$ & $20+52$ & $21+0$ & $6+27$ \\
Percolation into bedrock [mm] & 50 & 53 & 80 & 60 & 26 & 46 \\
\hline
\end{tabular}

\section{Experimental slopes}

The experiments were replicated across three hill slopes with different soils and geology to cover different subsurface flow mechanisms. At all sites, substantial SSF was expected according to the decision scheme of Scherrer and Naef (2003). The three test sites, listed in Table 3, were situated in the Swiss Plateau region. Mean annual temperature in this region is between $6^{\circ} \mathrm{C}$ and $8^{\circ} \mathrm{C}$, mean annual precipitation ranges from $1000 \mathrm{~mm}$ to $1500 \mathrm{~mm}$ and evapotranspiration is about $40 \%$ of annual precipitation. The Swiss Plateau is mainly formed by "Molasse", deposited at the border of the Alps and consisting of sandstones, marl, and conglomerates. These sedimentary rocks are in large parts overlain by glacial till and fluvial deposits. Details on geology and soil properties are given in Table 4 . The pipette method was applied to determine percentages of sand ( $63 \mu \mathrm{m}$ to $2 \mathrm{~mm})$, silt $(2 \mu \mathrm{m}$ to $63 \mu \mathrm{m})$ and clay $(<2 \mu \mathrm{m})$. Packing density and percentage of coarse fragments were estimated according to Finnern et al. (1994). Density of vertical macropores was assessed by counting the number of macropores (radius $\geq 1 \mathrm{~mm}$ ) in horizontal cross-sections over an area of $2500 \mathrm{~cm}^{2}$ at different soil depths (every $20 \mathrm{~cm}$ ). The cross-sections were carefully excavated and cleaned with a brush to avoid destruction or clogging of smaller macropores. As all three sites are extensively used as meadow, vegetation is similar and consists of plants typical for middle-Europe rich pastures.
A related study analyses and explains the substantial variation of SSF formation at these sites (Kienzler and Naef, 2008; Fig. 2). The individual response depended on the degree of direct or indirect feeding of SSF. Direct feeding of SSF means that precipitation feeds directly into an extended system of large and well-connected vertical and lateral preferential flow paths with little interaction with the soil matrix. Therefore, SSF responds quickly, shows high flow velocities and contains little pre-event water (site Koblenz in Fig. 2). Indirect feeding, as observed at Im Sertel, means that water infiltrates first into the soil matrix and that subsurface flow originates from the saturated soil matrix. In this case, the SSF response to precipitation is delayed and contains little event water. Response at Lutertal and Schluessberg was between these extremes. At Schluessberg, parts of the subsoil saturated during low-intensity rainfall and SSF response was moderately delayed and contained about $60 \%$ of pre-event water. The SSF response at Lutertal was also moderately delayed and contained about $50 \%$ of pre-event water. Here, outflow from individual soil pipes started at different times and contained different amounts of pre-event water. Pipes with delayed response had higher concentrations of pre-event water than pipes with fast response. This indicates that the latter were fed directly from precipitation, whereas the former were fed indirectly from saturated parts of the soil (Kienzler and Naef, 2008). 
Table 3. Locations of the experimental slopes.

\begin{tabular}{lccc}
\hline Site & Schluessberg & Im Sertel & Lutertal \\
\hline Location (Long./ Lat:) & $8^{\circ} 45^{\prime} 06^{\prime \prime} / 47^{\circ} 16^{\prime} 48^{\prime \prime}$ & $7^{\circ} 58^{\prime} 49^{\prime \prime} / 47^{\circ} 14^{\prime} 17^{\prime \prime}$ & $8^{\circ} 00^{\prime} 37^{\prime \prime} / 47^{\circ} 14^{\prime} 10^{\prime \prime}$ \\
Altitude [m a.s.l.] & 520 & 540 & 690 \\
Aspect & $\mathrm{SW}$ & $\mathrm{NE}$ & $\mathrm{S}$ \\
Slope [\%] & 28 & 40 & 30 \\
Land use & meadow & meadow & meadow \\
\hline
\end{tabular}

Table 4. Soil characteristics of the experimental slopes.

\begin{tabular}{|c|c|c|c|c|c|c|c|c|}
\hline \multicolumn{2}{|c|}{ Site } & \multicolumn{3}{|c|}{ Soil classification } & \multicolumn{4}{|c|}{ Geological parent material } \\
\hline \multirow{2}{*}{ Depth [cm] } & \multirow{2}{*}{ Horizon } & \multicolumn{3}{|c|}{ particle size distribution [\%] } & \multirow{2}{*}{ coarse fragments [\%] } & \multirow{2}{*}{ packing density $\left[\mathrm{g} \mathrm{cm}^{-3}\right]$} & \multirow{2}{*}{ macropore density $\left[\mathrm{m}^{-2}\right]$} & \multirow{2}{*}{$\mathrm{pH}$} \\
\hline & & Sand & Silt & Clay & & & & \\
\hline \multicolumn{2}{|c|}{ Schluessberg } & \multicolumn{3}{|c|}{ Calcaric cambisol } & \multicolumn{4}{|c|}{ Ground moraine } \\
\hline $0-10$ & $\mathrm{Ah}$ & 34 & 34 & 32 & 3 & 1.1 & 224 & 5 \\
\hline $11-24$ & $\mathrm{~A} / \mathrm{B}$ & 34 & 34 & 32 & 5 & 1.3 & 136 & 5 \\
\hline $24-80$ & $\mathrm{Bw}$ & 31 & 35 & 34 & 10 & 1.4 & 111 & 5 \\
\hline$>80$ & $\mathrm{C}$ & 31 & 35 & 34 & 15 & 2 & 35 & 8 \\
\hline \multicolumn{2}{|c|}{ Lutertal } & \multicolumn{3}{|c|}{ Cambisol } & \multicolumn{4}{|c|}{ Siltstone of "Oeningien" Molasse } \\
\hline $0-10$ & A & 26 & 51 & 23 & $<1$ & 1.2 & 184 & 5 \\
\hline $10-25$ & B & 26 & 51 & 23 & $<1$ & 1.3 & 248 & 6 \\
\hline $25-40$ & $\mathrm{~B} / \mathrm{Cv}$ & 26 & 51 & 23 & $2-5$ & 1.4 & 132 & 6 \\
\hline$>42$ & $\mathrm{C}$ & & & & & 2.2 & 0 & 7 \\
\hline \multicolumn{2}{|c|}{ Im Sertel } & \multicolumn{3}{|c|}{ Cambisol } & \multicolumn{4}{|c|}{ Sandstone of "Helvetien" Molasse } \\
\hline $0-20$ & A & 41 & 29 & 30 & $<1$ & 1.2 & 284 & 5 \\
\hline $20-80$ & B & 47 & 29 & 24 & $<1$ & 1.3 & 216 & 5 \\
\hline $80-160$ & $\mathrm{~B} / \mathrm{Cv}$ & 51 & 27 & 22 & $<1$ & 1.3 & 344 & 5 \\
\hline $160-270$ & $\mathrm{Cv}$ & & & & & 1.8 & 126 & 8 \\
\hline$>270$ & $\mathrm{C}$ & & & & & 2.2 & & 8 \\
\hline
\end{tabular}

\section{Antecedent precipitation and SSF formation}

\subsection{Results}

Figure 3 (left) compares cumulative runoff coefficients for overland flow and total subsurface flow in response to the follow-up experiments. With regard to the influence of antecedent precipitation, the different sites showed distinct differences. Runoff response was independent from antecedent precipitation at Schluessberg as well as at Lutertal. By contrast, at Im Sertel no runoff at all (neither surface nor subsurface) was produced during the first experiment, whereas subsurface flow from a thin weathered layer above the underlying sandstone started after a few $\mathrm{mm}$ of precipitation during the follow-up experiment (Table 1, Fig. 3, left). Small differences in antecedent soil moisture content were detected between the first and the second experiment at Schluessberg as well as at Lutertal. This contrasts with Im Sertel where antecedent soil moisture content was substantially in- creased before the second experiment (Table 1). The impact of drainage on soil moisture content, soil suction and water table after the first experiment is depicted by Fig. 3 (right). These results imply, that drainage at Im Sertel was considerably delayed in comparison to Schluessberg and Lutertal.

\subsection{Discussion}

What was the reason for the different influence of antecedent precipitation on the different experimental slopes? It can be understood by considering the different types of SSF formation (see Sect. 3). At Im Sertel, there was a delayed SSF response despite the high density of vertical macropores and the existence of a highly permeable layer. There was no direct preferential flow from the soil surface to the trench. Instead, infiltration from vertical macropores into the soil matrix occurred and lateral subsurface flow was initiated only after large parts of the subsoil were saturated. Therefore, during the first experiment, nearly all precipitation was 

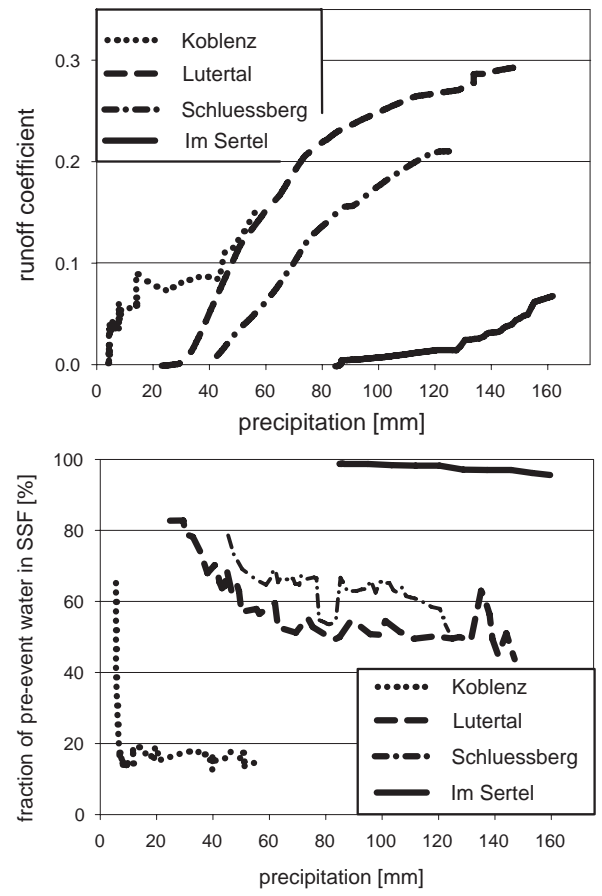

Fig. 2. Intercomparison of differently responding hillslopes during low-intensity precipitation (Table 2, Kienzler and Naef, 2008). Directly fed subsurface stormflow starts quickly and contains little pre-event water (Koblenz). The start of indirectly fed subsurface stormflow is delayed and consists mainly of pre-event water (Im Sertel). The responses at Lutertal and Schluessberg were between these extremes. Results of pre-event water fraction and cumulative runoff coefficient are plotted against precipitation sum.

retained in the subsoil, which reached almost saturated conditions (Fig. 6). After this first experiment, the saturated parts of the soil drained slowly (Fig. 3, right). Consequently, a small amount of precipitation could trigger SSF from the saturated subsoil during the follow-up experiment. At the two other sites, SSF was formed differently. As the interaction of preferential flow with the surrounding soil matrix was limited, the initiation of SSF was less dependent on saturation. SSF started already from small, saturated patches within the soil. After the experiment, these small patches were drained fast and effectively by preferential flow. Therefore, the soils showed a similar retention capacity during follow-up experiments and also antecedent moisture was comparable for both experiments.

Scherrer et al. (2007) concluded from sprinkling experiments on 18 different sites, that "the impact of antecedent wetness on the (total) runoff volume depends on the runoff process encountered". At some sites of their study, "a faster reaction under wet conditions was prevented by an efficient drainage system, which lowered the water table in the soil within a few hours", whereas other sites "reacted quite sensitively to antecedent wetness".
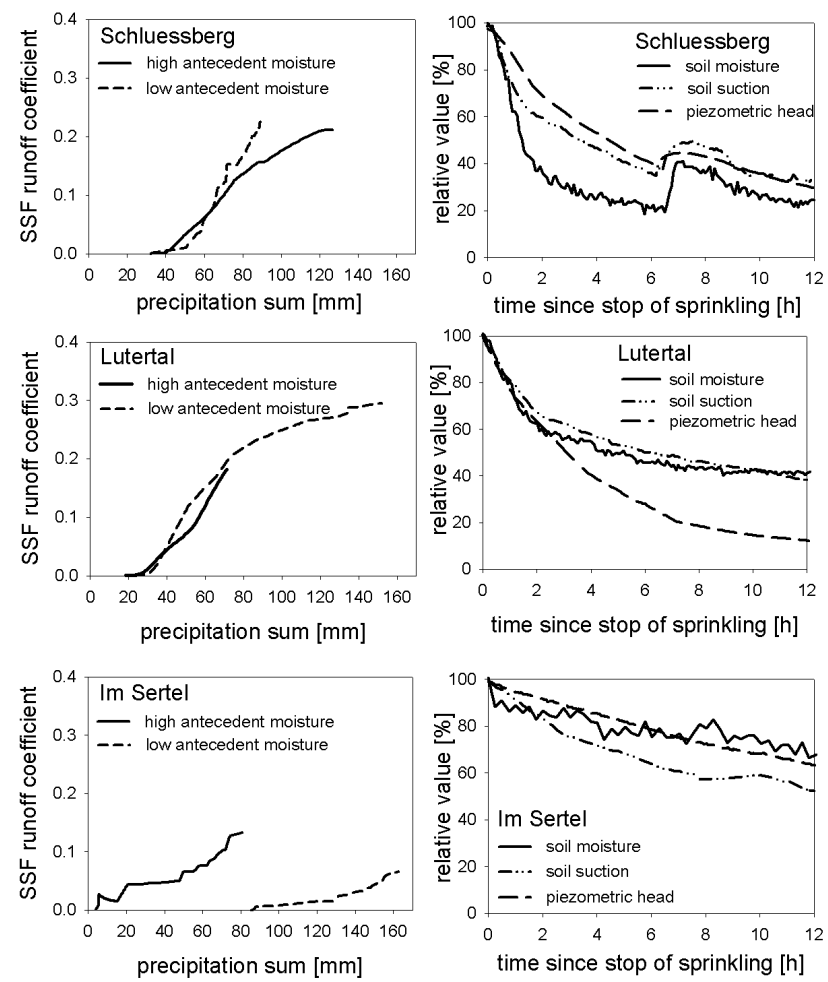

Fig. 3. Left: Comparison of cumulative runoff coefficients of overland flow (OF) and subsurface flow (SSF) in response to two followup sprinkling experiments with different antecedent precipitation. Right: The impact of drainage after sprinkling. Measurements at individual probes of soil moisture, soil suction and water level were averaged. To allow for comparison, not the absolute values, but percentages are given, where $100 \%$ represents values of soil suction, soil moisture content and piezometric head when sprinkling is completed and $0 \%$ represents values that were measured before the experiment.

These findings imply that the influence of antecedent precipitation on subsurface and surface runoff response depends on how SSF is formed. They show that parameters like the "antecedent precipitation index" have to be applied with caution in hydrological modeling, as high antecedent precipitation implies increased runoff response and high antecedent soil moisture for a limited number of hillslope settings only.

\section{Precipitation intensity and SSF formation}

\subsection{Results}

On all experimental slopes, substantial subsurface flow occurred during low as well as during high intensities, whereas (nearly) no overland flow occurred during low intensities but large amounts of overland flow during high intensities (Table 2, Fig. 4, left). At Schluessberg and at Im Sertel, additional subsurface flow paths were activated within the topsoil during high precipitation intensities. 

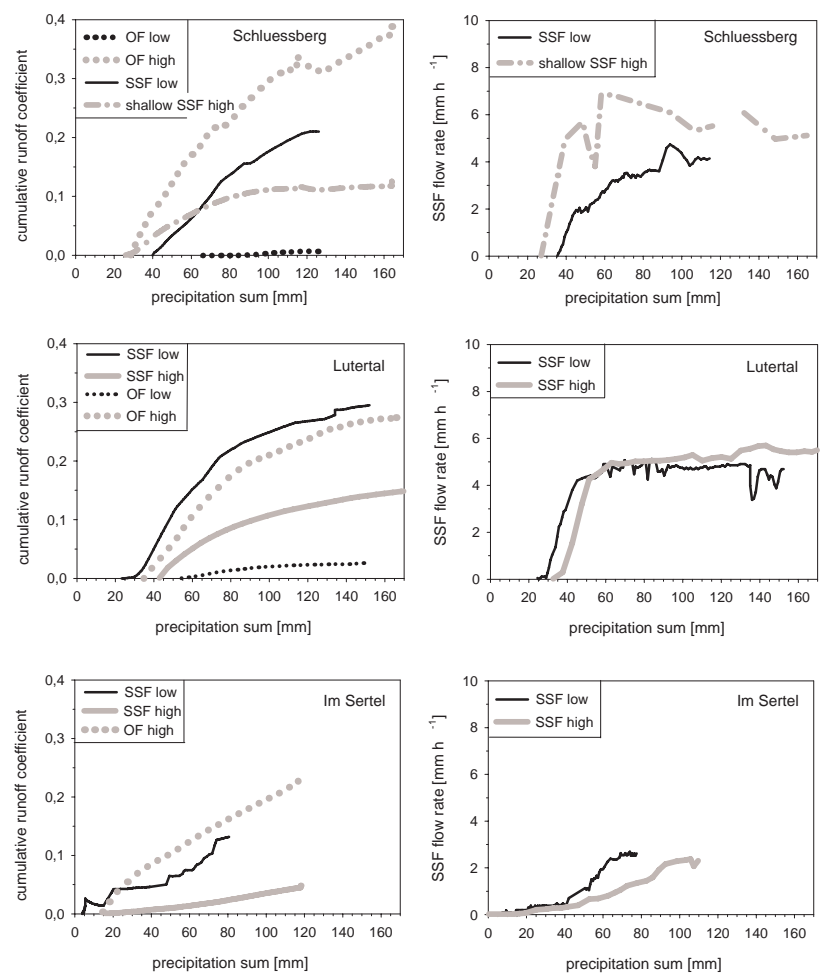

Fig. 4. Runoff response to low-intensity sprinkling and highintensity sprinkling. Compared are cumulative runoff coefficients (left) and SSF flow rates (right) for each experimental slope.

At Im Sertel, outflow from a thin weathered layer directly above the sandstone bedrock at $1.6 \mathrm{~m}$ depth and from a mouse hole at $0.7 \mathrm{~m}$ depth was observed during low precipitation intensity. Both flow components contained high percentages of pre-event water of more than 95\%. During the high-intensity experiment, the same flow paths were activated again with similar high fractions of pre-event water. Discharge from these flow paths was similar during both intensities (Fig. 4, right). In addition to this subsoil SSF, overland flow and flow within the topsoil were observed during the high-intensity experiment. This topsoil SSF occurred at $15-25 \mathrm{~cm}$ depth from two soil pipes with diameters of 10 $15 \mathrm{~mm}$ and contained less than $10 \%$ of pre-event water.

Different subsurface flow components were also observed at Schluessberg, where topsoil SSF to a depth of $40 \mathrm{~cm}$ and subsoil SSF to a depth of $150 \mathrm{~cm}$ were measured separately. During high precipitation intensity, outflow from five soil pipes with diameters of 4-8 $\mathrm{mm}$ was observed at a depth of $15-40 \mathrm{~cm}$. This topsoil SSF had low pre-event water content of $27 \%$ similar to overland flow and was not active during sprinkling with $10 \mathrm{~mm} \mathrm{~h}^{-1}$, when SSF occurred in the subsoil with more than $62 \%$ of pre-event water. An increase of the intensity to $20 \mathrm{~mm} \mathrm{~h}^{-1}$ at the end of the experiment triggered overland flow and caused a slight increase of subsoil SSF (Fig. 4, right).
At Lutertal, overland flow and subsurface flow occurred during both low and high intensities. No additional topsoil SSF occurred. Pre-event water content in SSF was similar during the different intensities (Kienzler and Naef, 2008). Also, maximum SSF discharge values were similar during different precipitation intensities and occurred after similar amounts of precipitation (Fig. 4, right).

A simple analysis was conducted to test whether a switch from matrix infiltration to macropore infiltration occurred due to the switch from low to high intensity. The point in time was determined for all TDR-probes and tensiometers when soil moisture content and soil suction started to increase. Then, the amount of water was calculated that infiltrated into the soil before this specific point in time. Figure 5 compares these amounts of infiltrated water for the different intensities and experimental slopes.

While this analysis reveals quick infiltration into the whole soil profile, the extent of the increase in soil moisture content varied distinctly at different depths (Fig. 6). At all sites, increase of soil moisture was observed mainly in the topsoil as well as in the subsoil above the underlying bedrock material. During high intensity, mainly topsoil moisture content increased strongly, while subsoil moisture content responded less pronounced. In contrast, during low intensity, subsoil moisture content increased strongly and topsoil water content increase was less pronounced.

\subsection{Discussion}

The similar responses of subsurface flow rate and pre-event water percentages indicate that subsoil SSF was hardly influenced by precipitation intensity. No switch to more preferential infiltration was detected during higher intensity by the simple infiltration analysis (Fig. 5). The maximum discharge of subsurface flow was already reached with low-intensity sprinkling and did not increase with higher precipitation intensity. However, the precipitation amounts and intensities applied in this study correspond to extreme rainfall events, which occur with a return frequency of more than 50-100 years $\left(10 \mathrm{~mm} \mathrm{~h}^{-1}\right)$ respectively $100-500$ years $\left(50 \mathrm{~mm} \mathrm{~h}^{-1}\right)$ in the study area (Röthlisberger et al., 1992). This implies that the observed subsurface flow with maxima between $3 \mathrm{~mm} \mathrm{~h}^{-1}$ (Im Sertel) and $6 \mathrm{~mm} \mathrm{~h}^{-1}$ (Lutertal) will deliver substantial contributions to total stormflow (OF + SSF) during most flood events. Only, the relevance of subsurface flow will be low during very extreme and rare events with highintensity precipitation, when overland flow will constitute the greatest part of total runoff. Uchida et al. (2001) listed similar maximum subsurface flow rates for several forested sites and attributed the limitations of the subsurface flow rates to geometry and hydraulic resistance of lateral subsurface flow paths. In our study, the occurrence of overland flow indicated that the limited infiltration rate could be responsible for subsurface flow limitation. However, it can only be speculated 

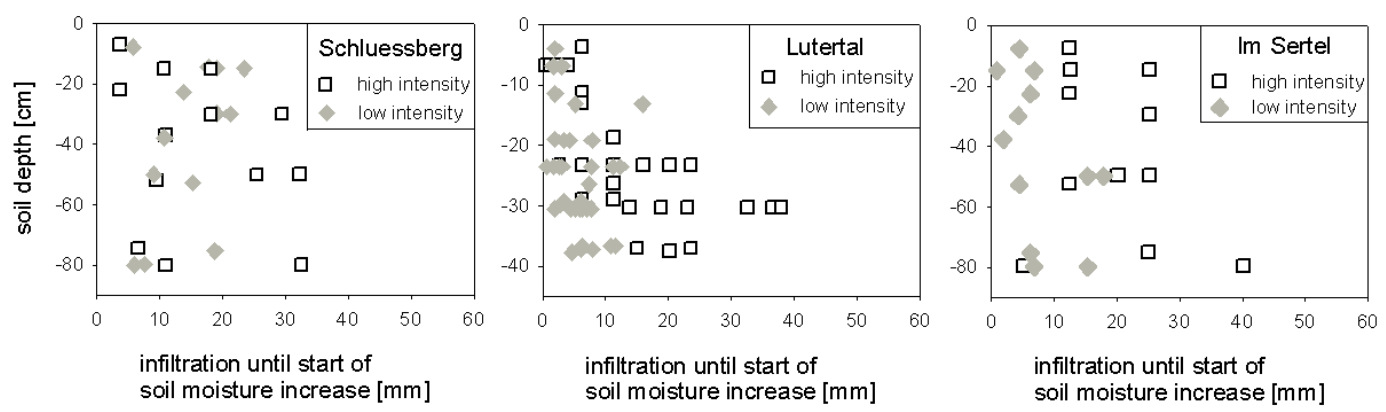

Fig. 5. Comparison of infiltration response to low-intensity and to high-intensity sprinkling. Depicted are sums of infiltration until start of soil moisture increase at different soil depths.
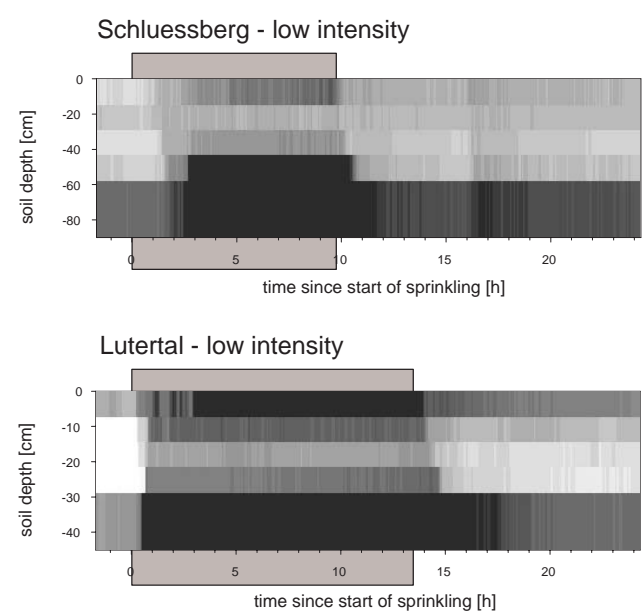

Im Sertel - low intensity

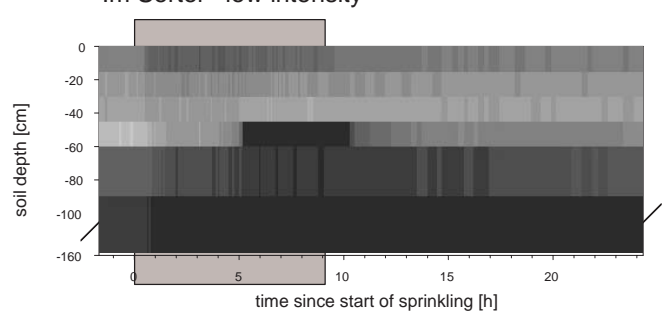

$50 \%$ saturation:

$\downarrow \quad$ soil moisture related

$100 \%$ to pore volume

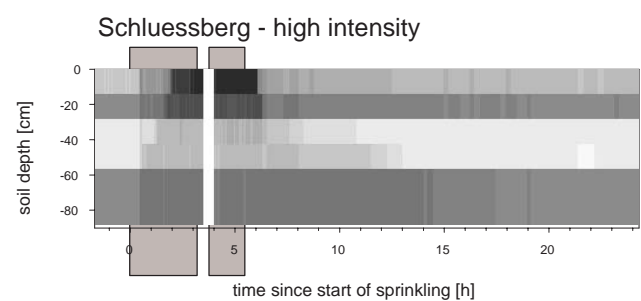

Lutertal - high intensity

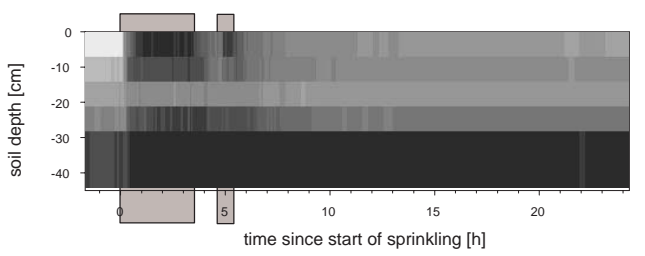

Im Sertel - high intensity

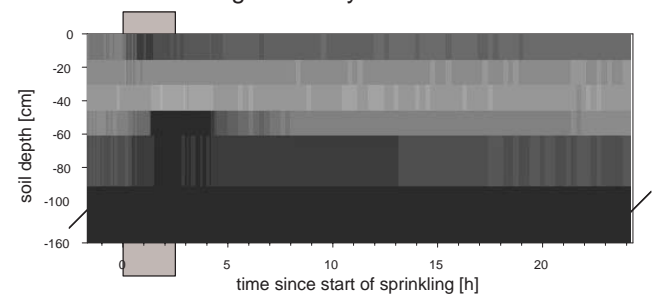

Fig. 6. The variation in soil moisture content as measured at different sites in response to different precipitation intensities. Values of soil moisture content are given in relation to pore volume, which was estimated according to Sponagel et al. (2005) from grain size distribution and packing density. Grey shaded boxes indicate sprinkling periods.

on whether this limitation of subsurface flow is the consequence of or the cause for limited infiltration rates.

Overland flow was not the result of complete saturation of the soil, as it started while a large part of the pore volume was still not saturated since tensiometers indicated unsaturated conditions. However, saturated conditions were observed in the uppermost topsoil layers of all three experimental slopes during high intensity and at Lutertal also during low intensity (Fig. 6). Despite the high macroporosity of the soil (Table 4), infiltration into the subsoil was limited and the topsoil saturated nearly independently from subsoil water content. Obviously, this topsoil saturation triggered overland flow. Also shallow subsurface flow (topsoil SSF) at Schluessberg and Im Sertel originated from the saturated topsoil as indicated 

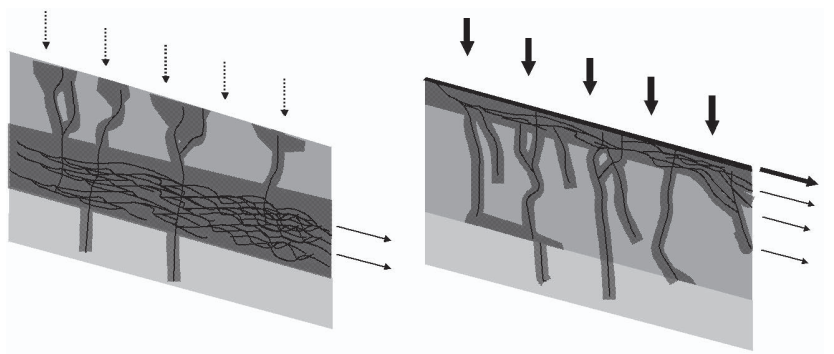

Fig. 7. Schematic concept of runoff formation during low precipitation intensity (left) and high intensity (right). As subsoil SSF is usually not changing when precipitation is increased, there may still be SSF even for high intensity. However, as large volumes of water flow off as overland flow and topsoil SSF, the initiation of subsoil SSF is considerably delayed and therefore not accounted for in this scheme.

by the similar pre-event water content of overland flow and of topsoil SSF. Infiltration into the subsoil was not completely inhibited and subsoil saturation developed above the underlying bedrock material. This saturation from below caused the formation of subsoil SSF. At Lutertal, topsoil saturation and saturation from below occurred at the same time. As a consequence, both, overland flow and subsurface flow occurred during both intensities. At Schluessberg however, no subsoil saturation developed during high-intensity sprinkling and topsoil saturation was considerably delayed during lowintensity sprinkling. Consequently, here, overland flow and topsoil SSF occurred during high-intensity sprinkling, while subsoil SSF formed during low-intensity sprinkling only. At Im Sertel, subsoil saturation and subsoil SSF were observed during high intensity as well as during low-intensity sprinkling. Topsoil saturation and subsequent triggering of overland flow and topsoil SSF were observed during the experiment with high-intensity sprinkling only.

In summary, different parts of the soil controlled flow formation depending on precipitation intensity (Fig. 7). During low intensity, saturation above the underlying bedrock was the most relevant process and subsoil SSF was the dominating runoff component. Subsoil SSF drained the soil continuously and delayed or prevented therefore a complete saturation of the whole soil profile and the initiation of overland flow and topsoil SSF during low intensity.

During higher intensity, topsoil saturation was the most relevant process and overland flow was the dominating runoff component. Such perched topsoil saturation has been observed repeatedly in podzolic soils with a thick organic Ohorizon overlaying a distinctive impermeable hardpan layer (e.g. Brown et al., 1999). This study shows that the development of perched saturation can occur due to slight vertical variations of macroporosity and packing density during high-intensity rainfall, influencing the different runoff components and the timing of these components. The similar pre-event water concentrations of overland flow and topsoil
SSF show that these flows were not separated but formed one well-mixed flow component that occurred before saturation of the whole soil profile, as only part of the available pore space was filled before runoff started.

\section{Conclusions}

The influence of antecedent precipitation on SSF response depends on how SSF is formed. Its influence is significant, when SSF is initiated only after large parts of the soil have been saturated, which are drained slowly after a rainfall event. SSF is less dependent on saturation, where it is formed in a more direct way from small, saturated patches, which can be drained efficiently. Consequently, the influence of antecedent precipitation on SSF response is weak at such sites. These findings imply that high antecedent precipitation correlates with high antecedent soil moisture and increased runoff response for a limited number of hillslope settings only. Therefore, a detailed knowledge of subsurface flow formation processes and its spatial variability is mandatory for the correct application of parameters like the "antecedent precipitation index" in catchment scale hydrological modeling.

Formation of subsurface stormflow was hardly influenced by the increase of precipitation intensity. As a consequence, subsurface flow rates were not increased by higher precipitation intensity. Such a limitation of subsurface discharge to site-specific maxima may be quite common.

Different soil structures determine runoff formation at different precipitation intensities as saturation may start in the subsoil at the soil-bedrock interface, but also within the topsoil during high precipitation intensity. Thus, timing and relevance of SSF response can change substantially at different intensities. The identification of such processes is straightforward in cases, where distinct impermeable soil layers occur, however, this study showed that perched topsoil saturation during high precipitation intensity may be triggered also by slight changes of macroporosity and packing density.

These findings imply that the influence of precipitation intensity on SSF response and total flow response can be highly nonlinear. Therefore, again, a detailed knowledge of SSF formation and subsurface flow rates is mandatory for the correct application of precipitation intensity - runoff relationships in catchment scale hydrological modeling.

Acknowledgement. This research was funded by the Swiss Federal Office for the Environment (BAFU) and the European Community Initiative INTERREG III $B$ in the framework of the WaReLaProject. F. Oberrauch, S. Agarwal, S. Wittmann, D. Carstens, M. Retter and D. Casper helped with the fieldwork. The referees A. Bronstert, M. Weiler and J. Kalma improved the manuscript a lot by providing helpful comments.

Edited by: J. D. Kalma 


\section{References}

Anderson, S. P., Dietrich, W. A., Montgomery, D. R., Torres, R., Conrad, M. E., and Loague, K.: Subsurface flow paths in a steep, unchanneled catchment, Water Resour. Res., 33(12), 2637-2653, 1997.

Beven, K. and Germann, P.: Macropores and water flow in soils, Water Resour. Res., 18(5), 1311-1325, 1982.

Bouma, M., Belmans, C. F. M., and Dekker, L. W.: Water infiltration and redistribution in a silt loam subsoil with vertical worm channels, Soil Sci. Soc. Am. J., 46, 917-921, 1982.

Bronstert, A. and Plate, E. J.: Modelling of runoff generation and soil moisture dynamics for hillslopes and micro-catchments, J. Hydrol., 198, 177-195, 1997.

Brown, V. A., McDonnell, J. J., Burns, D. A., and Kendall, C.: The role of event water, a rapid shallow flow component, and catchment size in summer stormflow, J. Hydrol., 217, 171-190, 1999.

Finnern, H., Grottenthaler, W., Kühn, D., Pälchen, W., Schraps, W. G., and Sponagel, H.: Bodenkundliche Kartieranleitung, 4. Aufl., 1994.

Jones, J. A. A., Richardson, J. M., and Jacob, H. J.: Factors controlling the distribution of piping in Britain: a reconnaissance, Geomorphology, 20, 289-306, 1997.

Jones, J. A. A. and Connelly, L. J.: A semi-distributed simulation model for natural pipeflow, J. Hydrol., 262, 28-49, 2002.

Kienzler, P. M. and Naef, F.: Subsurface storm flow formation at different hillslopes and implications for the "old water paradox", Hydrol. Processes, 22, 1, 104-116, 2008.

Kirkby, M. J.: Infiltration, Throughflow and Overland Flow, in: Water Earth and Man, edited by: Chorley, R. J., Taylor \& Francis, 215-227, 1969.

Lynch, J. A., Corbett, E. S., and Sopper, W. E.: Effects of antecedent soil moisture on stormflow volumes and timing, in: Proc. 3rd Int.Symp. in Hydrology (Colorado State University, Fort Collins, Colorado, USA), Water Resources Publications, Colorado, USA, 89-99, 1979.

McDonnell, J. J.: A rationale for old water discharge through macropores in a steep humid catchment, Water Resour. Res., 26, 2821-2832, 1990.

Noguchi, S., Tsuboyama, Y., Sidle, R., and Hosoda, I.: Subsurface runoff characteristics from a forest hillslope soil profile including macropores, Hitachi Ohta, Japan, Hydrol. Processes, 15, 21312149, 2001.

Peters, D. L., Buttle, J. M., Taylor, C. H. and LaZerte, J. M.: Runoff production in a forested, shallow soil, Canadian Shield basin, Water Resour. Res., 31, 1291-1304, 1995.
Retter, M., Kienzler, P. M., and Germann, P.: Vectors of subsurface storm flow in a layered hillslope during runoff initiation, Hydrol. Earth Syst. Sci., 10, 309-320, 2006, http://www.hydrol-earth-syst-sci.net/10/309/2006/.

Röthlisberger, G., Geiger, H., and Zeller, J.: Starkniederschläge im Schweizer Mittelland und Jura, Band 9., WSL, Birmensdorf, 1992.

Scherrer, S., Naef, F., Faeh, A. O., and Cordery, I.: Formation of runoff at the hillslope scale during intense precipitation, Hydrol. Earth Syst. Sci., 11, 907-922, 2007, http://www.hydrol-earth-syst-sci.net/11/907/2007/.

Scherrer, S. and Naef, F.: A decision scheme to identify dominant flow processes at the plot-scale for the evaluation of contributing areas at the catchments-scale, Hydrol. Processes, 17, 2, 391-401, 2003.

Sidle, R. C., Tsuboyama, Y., Noguchi, S., Hosoda, I., Fujieda, M., and Shimizu T.: Stormflow generation in steep forested headwaters: a linked hydrogeomorphic paradigm, Hydrol. Processes, 14, 369-385, 2000.

Trojan, M. D. and Linden, D. R.: Microrelief and rainfall effects on water and solute movement in earthworm burrows, Soil Sci. Soc. Am. J., 56, 727-733, 1992.

Uchida, T., Kosugi, K., and Mizuyama, T.: Runoff characteristics of pipeflow and effects of pipeflow on rainfall-runoff phenomena in a mountainous watershed, J. Hydrol., 222, 18-36, 1999.

Uchida, T., Kosugi, K., and Mizuyama, T.: Effects of pipeflow on hydrological process and its relation to landslide: a review of pipeflow studies in forested catchments, Hydrol. Processes, 15, 2151-2174, 2001.

Weiler, M., McDonnell, J. J., Tromp-van Meerveld, I., and Uchida, T.: Subsurface Stormflow, in: Encyclopedia of Hydrological Sciences, Volume 3, Part 10, edited by: Anderson, M. G. and McDonnell, J. J., Wiley and Sons, 2006.

Weiler, M.: Mechanisms controlling macropore flow during infiltration, Dissertation, ETH Zurich, http://e-collection.ethbib.ethz. ch/show?type=diss\&nr=14237, 2001.

Weiler, M. and Naef, F.: An experimental tracer study of the role of macropores in infiltration in grassland soils, Hydrol. Processes, 17, 477-493, 2003.

Whipkey, R. Z.: Subsurface stormflow from forested slopes, Bull. International Association Scientific Hydrology, 10, 74-85, 1967.

Woods, R. and Rowe, L.: The changing spatial variability of subsurface flow across a hillside, New Zealand Journal of Hydrology, 35(1), 51-86, 1996.

Zuidema, P. K.: Hydraulik der Abflussbildung während Starkniederschlägen, Mitteilungen der VAW, 79, 150 p., Dissertation, 1985. 